\title{
"Qual a base de conhecimentos que meu aluno deve ter?": uma experiência de ensino e aprendizagem de construção de indicadores educacionais*
}

Aline M. Reali

Claúdia R. Reyes

Elisabeth M. Martucci

MariadaGraçaMizukami

Emilia F. de Lima

ReginaTancredi

Roseli R. de Mello

Palavras-chave: indicadores educacionais; formação de professores; progressão continuada; séries iniciais

\section{Resumo}

A ponta al guns aspectos relacionados ao processo de construção col etiva de indicadores educacionais por professores das séries iniciais. Os dados foram obtidos por meio da real ização de uma experiência de ensino eaprendizagem junto a um grupo de professores de uma escola da rede pública do Estado de São Paulo. Como referência para a discussão realizada, os indicadores construídos para os diferentes componentes curriculares por professoras de 4a série do Ensino Fundamental são apresentados. Foi possível evidenciar a potencial idade dos processos de construção de indicadores educacionais, tanto no que se refere à definição de um quadro de referências sobre os conteúdos instrucionais que podem ser desenvolvidos em sal as de aula, de uma ferramenta para o monitoramento do ensino promovido e das bases para a progressão continuada, conforme objetivado por aquel a comunidade escolar. Foram ai nda objetivados subsídios importantes para promoção do desenvolvimento profissional das professoras e para a construção do projeto pedagógi co da escol a investigada.

\section{Introdução}

O presente artigo tem por objetivo apontar al guns aspectos evidenciados na construção deindicadores educacionais por uma comunidadeescolar. Mais especificamente, anal isam-se al guns dos resultados obtidos, tendo em vista as respostas das professoras e os processos de construção coletiva assim como as possibilidades de indicadores serem adotados como um dos meios paraa viabilização da progressão continuada de alunos das séries iniciais do ensino fundamental. Para exemplificar os resultados obtidos apresentam-se os indicadores construídos por um conjunto de professores de $4^{a}$ série. ${ }^{1}$

O trabal ho em pauta é parte de uma pesquisa-intervenção que se desenvolveu entre 1996 e 2000, surgida de uma parceria entre as autoras e 27 profissionais de uma escola das séries iniciais do ensino fundamental da rede estadual de uma cidade de médio porte do interior paulista. O projeto depesquisa mais amplo objetivava construir conhecimentos sobre processos de aprendizageme desenvolvimento profissional de professorese, simultaneamente, intervir no contexto em quetais processos ocorriam, de forma que conhecimentos pudessem ser construídos/reconstruídos colaborativamente entre as partici pantes pesquisadoras da universi dade e professoras da escola.

As professoras que partici param dessa pesquisa podem ser consideradas experientes, pois lecionam há mais de dez anos. Têm entre 30 e 48 anos. Nemtodas possuem curso superior e quando é este o caso, são licenciadas em Pedagogia; as demais 
concluíram a Habilitação Magistério. Geral mentetêm experiência em diferentes séries, embora al gumas tenham se especializado em uma ou outra, em virtude das atribuições anuais de aul as.

Os dadosquederam origem ao presente texto começaram a ser obtidos com as atividades real izadas pel o grupo de pesquisadoras, junto às professoras da escola parceira, na semana de planejamento do ano de 1998. Naquela oportunidade optou-se pelo desenvolvimento de um conjunto de atividades reunidas sob o tema "Construindo as Bases da Progressão Continuada", de modo a contemplar, num segundo momento, diferentes aspectos rel acionados à implementação denovas políticas públicas educacionais, tais como a Progressão Continuada, os Ciclos, a Prova Única, o Reforço de A prendizagem.

Tendo em vista a implementação do Sistema de Ciclos ea Progressão Continuada no Estado de São Paulo, considerou-se (pesquisadoras e professoras) ser imprescindível a compreensão e explicitação do currículo concebido como desejado pela escola, a partir do ponto de vista de seus professores, bem como a maneira pel a qual o mesmo seria implementado para que as bases da Progressão Conti nuada pudessem ser estabel ecidas.

Para tanto, era necessário que a instituição escolar indicasse o "grau de aquisições de conhecimentos ede competências" (Perrenoud, 1999) que jul gasse pertinente al cançar, tendo em vista o ciclo de ensino que desenvolvia: as quatro primeiras séries do ensino fundamental. Supunha-se ser rel evante o estabelecimento de objetivos educacionais bem definidos tendo como referênciaum determinado espaço-tempo de maneira que a cada aluno pudessem ser oferecidas possibilidades diferenciadas para aprender. A partir da real ização dessa atividade, entendia-se que a equipe escolar, representada essencialmente por seus professores, pudesse melhor compreender seus al unos, definir um quadro de referências sobre os conteúdos instrucionais desenvol vidos em sal as de aula eacompanhar os processos de ensino e aprendizagem por elaconduzidos.

Na pesquisa como um todo, consi derou-se cada uma das séries como um espaço-tempo del imitado, respeitando-se a maneira pela qual as professoras fundamentavam seu trabal ho pedagógico. Mesmo considerando o caráter mais flexível da organização do ensino por ciclos do que por seriação, há um conjunto de aprendizagens esperadas para o ciclo, considerado como um processo. Isso não exclui a necessidade de definir as a prendizagens esperadas em cada porção espaço-tempo (ano escolar) minimizando assim o risco de quea professora de cada série posterguea consecução das aprendizagens para a(s) série(s) seguinte(s). Isso pode provocar, de um lado, o acúmulo de exigências de aprendizagens no ano final do ciclo e, de outro lado, uma certa indi ferenciação em relação aos pontos de chegada intermediários. Essa idéia é coerente com a idéia dos mínimos necessários em vez de mínimos possíveis (Luckesi, 1995). Para esse autor,

[...] É preciso que a ação pedagógica em geral e a avaliação sejam racionalmente decididas. Para tanto, sugere-se que, tecnicamente, ao planejar suas atividades de ensino, o professor estabel eça previamente o mínimo necessário a ser aprendido efetivamente pelo aluno (p. 45).

A despeito dos conflitos naturais oriundos da organização por série, supunha-se que as possibilidades, as limitações, as necessidades pessoais, os ritmos de aprendizagem, entre outras características dos alunos, poderiam na realidade fomentar as aprendizagens caso fossem adequadamente trabal hadas. Como se tinha em mente o caráter flexível da organização em ciclos - de que "nem tudo seaprende do mesmo modo, no mesmo tempo nem com o mesmo trabaIho" (Zabala, 1998, p. 86) - , foram mantidas, em outro momento, discussões com as professoras partici pantes do projeto a respei to do como ensinar e como avaliar, tendo em consi deração as necessi dades eas características dos al unos.

Pressupunha-setambém queos diferentes componentes curriculares - tais como concebidos pela escola e os professores apresentam uma constituição epistemológica e socioistórica particular, ou seja, compõem esão reflexos da base de conhecimento para o ensino dos professores, os quais, por sua vez, determi nam em grande parte as práticas pedagógicas (Shulman, 1986).

Em linhas gerais, para a el aboração das bases da Progressão Continuada, definiu-se previamente qual era o conjunto deconhecimentos que os alunos de cada uma das quatro primei ras séries deveriam construir, nos diferentes componentes curriculares, ao 
$\overline{2 \text { Observeo queas professoras }}$ nessemomento responderam, tendoemvistaasérieparaaqua estavamlecionando.

3 Essasexperiênciassãosituações estruturadas deensino eaprendizagem, planejadas pelas pesquisadoras epelas professoras daescolaeimplementadas por estasúltimas, a partir detemas deinteresseindividual egrupal elencados por elasediscutidos coletivamente. São experiências circunscritas - que podem implicar ações em pequenos grupos de professoras ou nas salas deaula, envolvendo professora ealunos- , geralmente oriundas dedificul dades práticas relativas à compreensão de componentescurricularesou de desafios propostos pel o dia-adiadaescolaedas políticas públicas(Mizukami etal., 1998, p. 3), equesão usadas tanto como ferramentainvestigativa quanto formativa. Paraseu desenvolvimento, são adotadas diferentes fontes de dados incluindo observação, questionários, diá rios, registros escritos, análise documental, entreoutras.
Iongo do ano letivo, para então se estabele cer os requisitos mínimos que assegurariam a progressão para a série seguinte. Para tanto, propôs-sedeinício às professoras que respondessem individual menteà seguinte questão: "O que um aluno da ... série $\mathrm{e}^{2}$ deveria saber em termos de conteúdos ehabilidades, ao final do ano, em cada componente curricular, para acompanhar sem dificuldade a série seguinte?"

Numa segunda fase, às professoras de uma mesma série foi indicado que trabaIhassem na construção de respostas coletivas a partir de suas respostas individuais, compondo um quadro de referências para cada uma das séries, ou seja, um conjunto de indicadores educacionais.

Numa terceira e última fase, os quadros definidos para cada uma das quatro séries foram discutidos como conjunto das 27 professoras participantes do projeto, delineando-se, assim, o referencial pedagógico da escola com relação aos conteúdos curriculares mínimos desejáveis, tendo em vista a organização curricular por ela adotada e o ciclo de ensino trabal hado: as séries iniciais.

Consi derando a real ização dessas atividades, pretendia-sequeas professoras definissem claramente "os padrões mínimos de aprendizagem esperada para os seus al unos" (São Paulo, 1998, p. 4) de acordo com recomendação da Secretaria de Estado da Educação deSão Paulo no documento Escola de Cara Nova. Mais especificamente, ao determinarema basedeconhecimento queos alunos deveriam aprender, estavam definindo maneiras objetivas deacompanhar a progressão da aprendizagem dos al unos.

A partir das atividades desenvolvidas, buscou-se a el aboração de indicadores de processos, isto é, dados sobre o currículo desenvolvido por parte da escola - informações sobre o quê, o quanto, o como os alunos devem aprender ou estão aprendendo. Consi derou-serelevante criar condições favoráveis para quea escola construísseum sistema interno de controle ou monitoramento sobre o que os al unos realmente aprendem, ou devem aprender, isto é, seus próprios indi cadores educacionais.

A construção e o uso de indicadores educacionais no nível das escolas - como aqui defendido - são concebidos como mecanismos de apoio aos processos individuais e coletivos detomada dedecisões relacionados especial menteao currículo a ser desenvol vido, às ações referentes ao desenvolvimento profissional de professores e outros profissionais da educação, ao diagnóstico de dificuldades ou problemas enfrentados no cotidiano da escola, entreoutros.

O desenvolvimento das atividades mencionadas foi compreendido como uma experiência de ensino e aprendizagem ${ }^{3}$ (Mizukami et al., 1998) em que se pretendeu buscar respostas para as seguintes questões:

- O que professores consideram relevantequeseus al unos aprendamtendo em vista os diferentes componentes curriculares das séries iniciais?

- O que é considerado rel evante para um professor de uma sérieétambém considerado por outros professores da mesma série?

- O que é considerado relevante para um componente curricular em uma sérieéconsiderado rel evantepara as outras séries?

\section{Alguns aportes teórico- metodológicos}

São apresentadas a seguir as i déias principais quenortearama construção deindicadores educacionais por professores de uma comunidadeescolar, bem como aquelas referentes ao desenvolvimento da pesquisa mais amplaàqual estetexto se relaciona.

\subsection{A construção deindicadores educacionais próprios pela escola}

No Brasil, as diversas agências responsáveis pelo del ineamento eacompanhamento de políticas públicas têm pautado suas decisões em indicadores relativos aos produtos do processo ensino eaprendizagem, como éo caso dosíndices de retenção, aprovação, abandono, as notas obti das em provas aplicadas a um grande contingente da população escolar, ou mesmo o custo-al uno.

Freqüentementesão estabel ecidas relações de causa e efeito entre as diferentes variáveis consideradas como contribuintes para o uso "instrumental " dos indicadores, conformeBryk eHermanson (1993), citados por Ogawa e Collon (1998). Nesses casos, a mel horia educacional émuitas vezes concebida como um projeto de engenharia em que 
os indicadores educacionais informam a construção de políticas públicas racionais. Os indicadores são percebidos como elementos que representam as rel ações entre os seus vários componentes e que oferecem informação sobre aspectos críticos. Nessa perspectiva os sistemas de indicadores pautam-seem um modelo conceitual pré-definido do processo deescol arização. Para cada um dos componentes do modelo são construídos indicadores que possi bilitam a análise das rel ações existentes entre eles. No geral essas rel ações são percebi das como causais (quanto mai or investimento financeiro nas condições deensino mel hor rendimento acadêmico, por exemplo) eos processos educacionais são compreendidos, medidos e representados por meio de dados numéricos.

Alternativamente e de modo complementar, quadros de referência podem ser construídos, tendo em vista a el aboração deum sistema deindicadores educacionais. Nestes casos, el ementos-chave do processo de escolarização podem ser apreendidos sem ater-sea um determi nado model o pré definido. A definição de um quadro dereferências nesse formato não implica o estabel ecimento de relações causais entre os vários componentes, não favorece o uso instrumental dos resultados obtidos e tampouco oferecea prescrição deum remé dio. Oferece, habitual mente, informações importantes para fomentar a discussão sobre um dado sistema educacional, pois são enfatizados dados sobre as características organizacionais e instrucionais da escola, como a qualidade do currículo e os seus objetivos (Ogawa, Collon, 1998).

A existência deindicadores de processos próprios de uma escola pode oferecer informações que favoreçam a reflexão da comunidade escolar quanto às atividades por el a desenvolvidas; quanto aos conceitos e val ores preval ecentes sobre aprendizagem, ensi no, prática pedagógica, organização curricular, políticas acadêmicas; quanto à natureza das relações sociais mantidas entre seus membros. Pode proporcionar, principalmente, el ementos para a construção deações específicas, tendo em vista a cultura própria de cada contexto escolar e as características de seus membros (Bryk, Hermanson, 1993).

Um conjunto de indicadores educacionais próprios podeter, ainda, a função de oferecer subsídios para a formulação e definição de objetivos educacionais, de padrões de desempenho desejáveis e como estes podem ser implementados por uma determinada comunidadeescolar.

Paraconstruir indicadores segundo esse formato, parece essencial que a escola se organize estabel eça col etivamenteos conteúdos específicos a serem ensinados e aprendidos pel os al unos. E, nessa tarefa, é rel evante definir não apenas o quê deveser aprendido (o conteúdo), mas também o quanto (em que grau de proficiência), o como (de que maneira) e o por que os alunos devem aprender.

O levantamento destes aspectos pode compor os passos iniciais de uma descrição detal hada do que ocorre numa dada realidade educacional, tendo em vista al guns critérios previamente definidos e considerando um certo período de tempo. Podem ainda atuar no modo como os professores pensameagem (Reali, 2001), particularmente quando são consideradas as decisões no âmbito da sala deaula, pois podem oferecer subsídios para o estabel ecimento de novas visões e expectativas sobre os al unos e sua aprendizagem (Bottani, Tuijnman, 1994).

O conjunto de competências ${ }^{4}$ conside radas rel evantes por parte da comunidade escolar, de certa maneira, direciona o quêé ensinado ea sua sistematização poderesultar em quadros referenciais codificados do currículo e suas metas ou indicadores de currículo.

O currículo pode ser compreendido como o projeto educativo queérealizado nas aulas (Gimeno Sacristán, Pérez Gómez, 1998) ena escola como um todo. Entretanto, muitas vezes éconcebi do como apenas um plano operacional, tendo em consideração o contexto de sua real ização e outros aspectos que condicionam a sua efetivação eque inclui o conteúdo, as ações e comportamentos esperados de professores e deal unos, o material a ser utilizado (livros di dáticos, exercícios, etc) eas estratégi as de ensino.

No presente trabalho, de modo similar ao proposto pela Comission on Behavioral and Social Sciences and Education, dos EUA, citado pelo National Research Council (1988), o termo currículo refere-se principalmente aos conteúdos específicos, aos conteúdos do currículo formal que são em linhas gerais definidos pelas políticas públicas, pel os sistemas deensino ou escolas. Os conteúdos do currículo geral mente re presentama associação de diversas influências: os fatos históricos precedentes, a visão dos educadores, as forças do mercado,

\footnotetext{
Competência éaqui compreendida segundo a concepção de Perrenoud (2000, p. 15), ou seja como "capacidadedemobilizar diversos recursos cognitivos para enfrentar umtipo desituação".
} 
o desejo dos pais e outros grupos da comunidade, as recomendações do estado e as percepções sobre o que os al unos necessitam saber.

Segundo Porter e Smithson (2001), o currículo podeainda ser expresso de diferentes formas: os planos e as diretrizes de um Estado ou de uma determinada política; o conteúdo de livros di dáticos; o conteúdo apresentado ao al uno e o conteúdo aprendido. As diretrizes curriculares, os livros didáticos eoutros materiai s escritos - como os conteúdos das aval iações - que podem ser usados para a instrução correspondem ao currículo pretendido (intended), ou seja, o queas ferramentas políticas definem como sendo o que deve ser ensinado. O currículo implementado (enacted) corresponde aos conteúdos curriculares que os alunos vivenciam em sala de aula e, como tal, é extremamente importante apreendêlo. O currículo avaliado (assessed) poderia ser concebido estando diretamenter relacionado ao currículo pretendido e diz respeito ao queémedido por meio de aval iações externas, como, no caso do Brasil, o Sistema de Aval iação de Rendimento Escol ar do Estado deSão Paulo (Saresp) e o Sistema Nacional de Avaliação da Educação Básica (Saeb). O currículo aprendido (learned) correspondeaos conteúdos queforam efetivamente aprendidos, assim como em que grau de proficiência, por parte dos al unos. A distinção desses quatro componentes do currículo permite o exame cuidadoso de como o mesmo se apresenta ea comparação deseus componentes em diferentes momentos econtextos.

Consi derando as ati vi dades propostas às professoras partici pantes da investigação, assumiu-se que as respostas por elas construídas coletivamentecorresponderiam aos objetivos dos diferentes componentes curriculares para cada uma das quatro séries, ou seja, corresponderiam, em parte, à explicitação do currícul o pretendido.

Conforme Giroux (1997), os objetivos que os professores se propõem a atingir quando desenvolvem seu trabal ho junto aos alunos podem ser de duas naturezas: os macroobjetivos e os microobjetivos. O primeiro tipo ofereceria

[...] um sistema de classi ficação destinado a ajudar estudantes e professores a ir al ém das noções de aprendizagem limitadas pelos parâmetros de uma determinada disciplina ou curso [...] são destinados a fornecer os blocos teóricos de construção que permitirão aos estudantes estabelecerem conexões entre os métodos, conteúdos eestrutura de um curso e sua importância para a reali dade social mais ampla [...] incluíram diferenciar o conhecimento diretivo do produtivo, explicitar o currículo ocul to eajudar os estudantes a desenvolverem uma consciência crítica e política [...] servem como conceitos mediadores que elucidam o significado ea importância que os microobjetivos poderiam ter em relação às estruturas sociopolíticas que existem fora da sala de aula [...] são destinados a fornecer um paradigma que permita que os estudantes questionem o propósito evaIor dos microobjetivos, não apenas na medida em que se aplicam a um determi nado curso, mas tambémà sociedademais ampla (p. 84-88).

O segundo tipo, ou os microobjetivos, representaria geralmente os objetivos de cursos tradicionais esão

[...] normalmente limitados pela especificidade ou estreiteza de seu propósito, o qual é moldado pela singularidade do curso que são destinados a seguir [...] consistem daquel as concepções impostas queconstituem o núcl eo deuma dada disciplina e definem seu curso de investigação [...] o que está em questão não é tanto a validade destes objetivos específicos esim seu rel acionamento com um conjunto mais amplo de objetivos, os macroobjetivos (p. 84).

Considerou-se, ainda, que o nível de conhecimento expresso pelas professoras investigadas corresponderia ao que deveria ser atingi do pel os al unos o que, segundo as Matrizes Curriculares de Referência (Pestana, 1999), contempla a existência de três níveis distintos de ações eoperações, a saber:

- nível básico, que corresponderia "às ações que possibilitam a apreensão das características e propriedades permanentes e simultâneas de objetos comparáveis, isto é, que propiciama construção de concei tos" (p. 10);

- nível operacional, que seriam as "ações coordenadas que pressupõem o estabel ecimento derel ações entreos objetos (...) mais que o 'saber fazer', supõem al guma tomada deconsciência dos instrumentos e procedimentos utilizados, possibilitando a sua aplicação a outros contextos" (p. 10); - nível gl obal, que se caracterizaria por "ações e operações mais complexas, 
queenvolvem a aplicação de conhecimentos e situações diferentes ea resolução de problemas inéditos" (p. 11).

\section{Por fim, considerou-seque}

[...] aquil o queos alunos aprendem na situação escolar - etambém aquil o que deixam de aprender - é mais amplo que [...] [a] acepção de currículo como especificação de temas e conteúdos de todo o tipo. Isto é, o currículo real é mais amplo quequal quer 'documento' no qual se reflitam os objetivos e planos [...] (Gimeno Sacristán, 1995, p. 86).

Desse modo, adotou-se como pressuposto que o ensino mi nistrado em sal a de aula transcendetoda e qual quer intenção e, por isso, qual quer descrição sobre o que seria desejável éinsuficiente para oferecer uma idéia fiel do quevai ocorrer. Sob essa ótica, entendeu-sequeas respostas oferecidas pel as professoras corresponderiam apenas parcialmente ao universo dos processos de ensino e aprendizagem vivenciados pelos alunos e por elas conduzido, isto éao currículo desenvolvido, também denominado currículo real ou currículo-em-ação.

Para a real ização das anál ises, os conteúdos indicados foram consi derados como estando relacionados aos tercei ro e quarto níveis de concretização curricular apontados no capítulo referente aos Princípios e Fundamentos dos Parâmetros Curriculares Nacionais (Inep, 2001). Isso implicou conceber a presente experiência de ensino e aprendizagem como parte da el aboração de uma proposta curricular da instituição escolar - o projeto educativo da escola - e, especificamente, da preparação das atividades de ensino e aprendizagem na sal a de aula.

De acordo com os PCN (Inep, 2001), o projeto educativo da escola é entendido como

[...] a expressão da identidade de cada escola em um processo dinâmico de discussão, reflexão e elaboração contínua. Esse processo deve contar com a participação de toda a equipe pedagógica, buscando um comprometimento de todos com o trabal ho real izado, com os propósitos discutidos e com a adequação detal projeto às características sociais e culturais da realidade em que a escola está inserida. É no âmbito do projeto educativo que professores e equipe técnica discutem e organizam os objetivos, critérios de avaliação [...] (p. 37)

O momento da implementação dos programas na sala de aula compõe um outro nível de concretização curricular eéassim descrito no mesmo documento:

\section{[... é quando o professor, segundo as me- tas estabel eci das na [terceira] fase, [...], faz sua programação, adequando-a àquele grupo específico de al unos [...]. Apesar da responsabilidade ser essencialmente de cada professor, éfundamental queesta seja compartilhada com a equipe da escola por mei o da co-responsabilidade estabel ecida no projeto educativo (p. 38).}

A definição de indicadores de currículo por uma comunidade escolar, segundo os mol des aqui advogados, poderesultar em diferentes usos por diversos segmentos da escola. Um del es seria definir a natureza das oportunidades educacionais oferecidas e os modos desua implementação. Um segundo uso seria a definição de um instrumento de aval iação para a real ização demudanças/reformas educacionais na escola. Um terceiro uso estaria vinculado ao estabel ecimento de uma ferramenta que permitiria olevantamento de hipóteses sobre os níveis de proficiência atingi dos por partedos al unos, tendo em vista os conteúdos trabal hados e a sua adequação.

Para os responsáveis pelos sistemas educacionais, o uso de indicadores de currículo pode oferecer informações sobre a "saúde" do sistema, bem como para a aval iação de iniciativas políticas sobre o ensino. Os dados de um tal sistema de indicadores pode proporcionar informações importantes para programas de desenvol vimento profissional e processos reflexivos sobre práticas pedagógicas de professores (Porter, Smithson, 2001).

Para a construção de um sistema de indicadores de currículo, diversas ferramentas podem ser adotadas. A observação das práticas de sal a de aula e os registros constantes nos diários de professores seriam duas fontes de informação interessantes. Nesses casos, diversas dimensões do currícul o podem ser apreendi das de modo detal hado, a despeito da necessi dade dese obter um conjunto el evado de dados para possi bi itar a composição de um quadro completo sobre o queéensi nado. Pode-se, ainda, lançar mão de certos descritores como os tópicos de 
conteú do abordados em um determinado período de tempo ou etapa do processo de escolarização. As demandas cognitivas impostas aos al unos e os modos de apresentação/desenvol vimento dos conteúdos poderiam compor outros conjuntos de informações importantes. Nesses casos, o professor é o principal informante, tendo em vista o seu papel nas decisões sobre o quê, o quanto e de que forma o que deve ser ensinado vai ser ensinado.

As mai ores dificuldades na elaboração e implementação de indicadores de currícul o por meio de descritores correspondem à compreensão precisa, por parte daqueles que não partici pam daquel a comunidade, da linguagem adotada pelos professores para descrever suas práticas. Isso parece especial mente verdadeiro quando o foco de análise diz respeito ao modo pelo qual o conteúdo étrabal hado, ou seja, sobre o conhecimento pedagógico de conteúdo (Shulman, 1987, 1986), isto é, como o conteúdo específico a ser ensinado étransformado em conteúdo aprendido. Essetipo de conhecimento incluiria as representações, as ilustrações, os exemplos, explanações e demonstrações apresentadas pel os professores para ensinar. É um tipo de conhecimento que se rel aciona às concepções básicas do professor a respeito dos propósitos de ensinar uma matéria específica, do que seria necessário que os al unos aprendessem, de estratégias, de concepções equivocadas ou concepções al ternativas dos al unos.

Alguns dados sobre o contexto investigado indicam que aquelas professoras usual mente definiam mais claramenteo quêé ensinado por meio da indicação da forma pela qual o ensino ocorreu/iria ocorrer. Isso aconteceu possivel menteporque, para muitos professores, essa inter-relação entre 0 quê e o como foi ensinado seja al go percebido como natural e indissociável (Mizukami et al., 2002) embora nem sempre as indicações apresentadas como tal correspondessem ao conhecimento pedagógico de conteúdo mencionado.

Uma outra dificul dade derivada do uso de descritores corresponde ao pressuposto de que os professores se envolverão deforma mais acentuada (ese tornarão mais efe tivos) em atingir os objetivos estabel ecidos em termos dos desempenhos dos alunos quando o currícul o está claramente definido por meio deindicadores, o quenem sempre é evidenciado na prática. Muitos dos aspectos relacionados à implementação de certas diretrizes - como o currículo pretendido - permanecem externos às práticas pedagógicas dos professores. A sua nãoimplementação resulta muitas vezes de atitudes de hostilidade por parte dos professores, tendo em vista as conseqüências de sua utilização. Como exemplo, pode ser mencionada a recentequali ificação das escolas da rede pública do Estado de São Paulo em escol as verdes, amarelas evermel has, em função das notas obtidas pelos alunos no Saresp.

Por fim, destaca-sequea adoção de um bom sistema de indicadores educacionais, por si só, não faz diferença na aprendizagem dos al unos. Diversamente, a capacidade organizacional da escola - que envolve os conhecimentos e habilidades dos professores; o exercício do poder e da autoridade, isto é, a existência de uma liderança efetiva; o acesso a recursos técni cos efinanceiros; a autonomia organizacional para agir deacordo com as demandas I ocais; a existência de um compromisso col etivamentecompartilha do em definir o quê, em que grau e como os al unos devem aprender - parece compor um conjunto de variáveis mais rel evantes para a melhoria do ensi no e o conseqüente mel hor desempenho dos al unos. Esse complexo de ações abarca ainda a disposição da escola, representada por seus profissionais, emalterar suas práticas individuais ecol etivas.

\subsection{A aprendizagem profissional da docência, o pensamento de professores e a construção de novas práticas pedagógicas}

O modelo de pesquisa e intervenção adotado na condução do presente trabal ho implicou, para as pesquisadoras, conhecer a real idade em queas professoras atuavam, o que pensavam, o que faziam e por que o faziam para, colaborativamente, refl etir com elas sobre as situações vivenciadas e, caso necessário, construir formas de enfrentamento que considerassem as especificidades da escol a e da comuni dade. Adotou, como premissas, as idéias apresentadas a seguir.

A aprendizagem profissional da docência é composta por processos e não por eventos (Knowles, Cole, Presswood, 1994, p. 286). Esses processos são pautados em diversas experiências e modos de 
conhecimento iniciados antes da preparação formal, que prosseguemao longo da vida epermeiam toda a prática profissional sendo, deste modo, desenvolvimental. Nessa perspectiva, a aprendizagem da docênciaé entendida como um processo complexo que envolve, entre outros, fatores afetivos, cognitivos, éticos, de desempenho (Cole, Knowles, 1993).

O que um professor faz em sal a deaula é determi nado fundamental mente por um conjunto de recursos intel ectuais que ele traz para a situação, denomi nado base de conhecimento (Shulman, 1986, 1987). Diferentes tipos de conhecimento fundamentam a tomada de decisões dos professores, dentre os quais podemos destacar: o conhecimento de conteúdo específico (conceitos básicos de uma área de conhecimento incluindo como foi construído e estruturado o conhecimento de uma determinada disciplina); o conhecimento pedagógico geral (conhecimento dos objetivos, metas e propósitos educacionais, de ensino e aprendizagem, demanejo declasseeinteração com os al unos, de estratégias instrucionais, de como os al unos aprendem, de conhecimento curricular) eo conhecimento peda gógico de conteúdo, definido anteriormente.

Além disso, os comportamentos dos professores em sal a deaula eas interações que estabel ecem com os al unos estão relacionados funcionalmente ao contexto institucional e, nessesentido, espaço etempo são dimensões queestruturam o exercício profissional. Defato os professores, ao ensinarem, encontram-se constantemente monitorando o que ocorre durante a aula e agindo com baseem percepções einterpretações sobre as ocorrências (Eraut, 1994), real izando dessa maneira um "ensino em contexto" (Schoenfeld, 1997).

As ações pedagógicas podem estar relacionadas aos indicadores educacionais de currículo, por exemplo, no sentido em que estes podem influenciar as decisões dos professores em sala de aula por meio de revisões das práticas pedagógicas. Paratanto, os indicadores devem oferecer informações sobre os conteúdos a serem aprendidos pel os al unos, sobre as condições para o seu ensino e sobre quais características do corpo discentedevem ser avaliadas. Para favorecer a suaformulação euso, a natureza do pensamento de professores, os seus processos de deci são assi m como suas crenças, visões e teorias pessoais devem ser consideradas por parte dos responsáveis por esses processos.
O modo de pensar deprofessores - suas crenças, val ores, entendimentos, pressupostos etc. - são meios importantes para se compreender o como e por queas pessoas agem do modo pelo qual o fazem. Essas idéias podem servir tanto de obstácul os para mudanças como também oferecer quadros de referência, e até pontos de partida, para interpretar e avaliar novas informações. As mudanças somenteocorrem quando os professores reconhecem discrepâncias entrea sua própria visão ea de outros sobre os diversos componentes dos processos deensino e aprendizagem (Zei chner, 1992) e dispõem de tempo e condições (McDiarmid, 1995) para fazêlo.

Nessa perspectiva, a escola, enquanto local de trabal ho, assumeimportância considerável na promoção do desenvol vimento profissional eda aprendizagem deseus profissionais. Nessa direção éfundamental que a escola adotedinâmicas, acompanheepropicie mudanças em função das suas necessidades e de seus objetivos, se constituindo como uma organização ${ }^{5}$ que aprende (Argyris, Schön, 1996).

Em termos metodológicos, ao buscar respostas às questões de pesquisa estabelecidas no presente trabal ho, foi necessário o desenvol vimento de atividades quefacilitassem a emergência dos conhecimentosecrenças das professoras partici pantes pel o grupo de pesquisadoras. No caso da presente experiência de ensino e aprendizagem, considerou-se que o que as professoras indicassem como desejável queseus alunos soubessem ao final do ano para ir bem na série seguinte corresponderia ao seu modo de pensar.

\section{Concepções individuais e coletivas de professoras sobre "o que é importante um aluno saber ao final do ano": ilustrando com dados da 4ạ série}

Para ilustrar os resultados obtidos com o desenvolvimento das atividades relacionadas àconstrução coletiva deindicadores educacionais por parte das professoras participantes da pesquisa mai sampla, apresentamse a seguir as respostas individuais de um conjunto de sete professoras da escola investigada que, à época da coleta dedados, lecionavam na 4ª série. Em suas respostas as

\footnotetext{
5 DeacordocomArgyreseSchön (1996), uma organização seca racteriza comotal, quando nela háprocedimentosestabelecidos em comum acordo entre seus membros, que permitamatomada dedecisões em nomeda coletividade; adelegaçãoaalguns membrosdaautoridadeparaagir pelo coletivo; ea existênciade um conjunto delimites entre essa col etividade e o resto do mundo.
} 
professoras abordaram os seguintes componentes curriculares: Língua Portuguesa, Matemática, Ciências, História e Geografia. Salienta-sequeEducação Artística eEduca ção Física não foram considerados por parte das professoras, pois aparentemente tratase, para elas, de componentes com caráter complementar em rel ação aos demais.

Optamos por apresentar os dados de 4a série com a finalidade de ilustrar os resultados gerais obtidos por essa experiência de ensino e aprendizagem. Isso porque foram evidenciados processos similares de el aboração de indicadores no caso das demais séries. Mesmo em se considerando essa evidência, pesou também como razão de escol ha da $4^{a}$ série o fato de ser nela que as decisões das professoras sobre aprovação e reprovação têm, possivel mente, um impacto real sobre a trajetória escolar dos al unos, devido ao regime de progressão continuadavigente. Outra razão refere-seao fato já al udido de que se percebe, nesta sé rie, um acúmulo de exigências de aprendizagens quenão foram conseguidas nos anos anteriores do ciclo. Os pontos de chegada intermediários, definidos como necessários, perdem as suas especificidades, o queacaba por ocasionar a transformação do ciclo em uma grande série de quatro anos caracterizada pel o ensino dos mínimos possíveis e não dos mínimos definidos como necessários.

Como já foi dito no início, vale destacar, novamente, quea coleta dos dados implicou que cada professora, num primeiro momento, respondesse por escrito, o que acreditava ser relevanteque "um al uno da... série ${ }^{6}$ deveria saber emtermos de conteúdos ehabilidades, ao final do ano, em cadacomponente curricular, para acompanhar sem dificuldade a série seguinte". Posteriormente, as professoras, reuni das por série, discutiram suas respostas individuais em confronto com as de seus pares. A pós discussões sobre a pertinência do conteúdo indicado por elas individual mente, defini ram em grupos os conteúdos previstos para o período de espaço-tempo considerado.

Para todas as sete professoras (100\%) de $4^{a}$ série, ler e interpretar variados tipos de textos, para assim, a partir deles, poder informar-se, divertir-se; compreender a unidade temática do texto e produzir diversos tipos de textos, demonstrando coesão, coerência, organização de diálogos, ortografia, pontuação, vocabulário; formular textos são as habilidades e os conteúdos que os al unos devem dominar em Língua Portuguesa para serem bem sucedidos na $5^{a}$ série. Expressar-se oralmente, com clareza e eficácia dentro de seu grupo social, compõe outro conjunto de habilidades apontado por cerca de $45 \%$ dessas professoras. De modo menos freqüente há indicação de outros conteúdos e habilidades a serem ensinados para esses al unos, como éo caso deopinar e discutir diversos tipos de textos e usar dicionário corretamente $(28,6 \%)$. Destaca-se não haver, nas respostas das professoras, indicações mais detalhadas sobre os níveis e/ou graus de dificuldadee compl exi dade com que tais habilidades e conteúdos devem ser domi nados.

Rel ativamenteà Matemática percebeuse, neste conjunto de professoras, a ênfase no domínio das quatro operações e a sua aplicação em situações problemas, tendo em vista os outros conteúdos que poderiam ser trabalhados nessa série. A parentemente, para elas, na 4a série, ser capaz de resolver operações fundamentais com compreensão das técnicas operatórias aplicando-as na resolução de problemas e efetuar e compreender as quatro operações fundamentais com os números naturais são os conteúdos e habilidades mais importantes posto terem sido indicados, respectivamente, por $85,7 \%$ e $71,4 \%$ das professoras. De maneira similar ao apontado para Língua Portuguesa, as professoras não ofereceram em suas respostas el ementos para que o nível de dificuldade ou complexidade de domínio desses conteúdos pudesse ser identificado.

Outros conteúdos e habilidades foram apontados por uma ou duas professoras, sugerindo a preocupação de sua parte para que os problemas apresentados aos al unos estivessem relacionados, deal guma maneira, às situações do cotidiano e possi bilitassem a ampliação do conjunto de conhecimentos dos alunos. Perceber a geometria como natural no contexto diário; realizar operações com porcentagem simples; dominar tabuadas; compreender o SND em suas ordens e classes; compreender os números racionais, operar com números racionais; encontrar respostas diferentes para várias situações problemáticas; questionar a realidade, formulando e tentar resolver problemas; utilizar pensamentos lógicos seriam exemplos desses cuidados.

A partir das indicações das professoras nota-se a sua preocupação em favorecer que seus alunos progridam na construção de conceitos e procedimentos matemáticos considerandoasérie estavamlecionando. 
conforme a orientação dos Parâmetros Curriculares Nacionais: Matemática (Inep, 2001). Entretanto, pouca ênfasefoi dadaaos demais conteúdos matemáticos considerados relevantes para essa fase de escolarização, como é o caso das noções sobre espaço, formas dimensionais e tridimensionais, indicadas como rel evantes, tendo em vista a geometria, ou de noções estatísticas básicas (Pestana, 1999).

Em Ciências aparentemente há uma maior valorização no desenvol vimento de um conjunto amplo de habilidades e conteúdos por parte dos alunos. Nas indicações real izadas pel as professoras de 4a sé rie, nota-se a menção de posturas, atitudes, val ores, posicionamentos sobre aspectos relacionados à vida, sobretudo aqueles relacionados à preservação do meio ambiente, como éo caso das respostas "conhecer o meio ambiente, protegendo-o"; "sentir-se parteintegrantedos ecossistemas terrestres, tendo noção desua partici pação nas transformações ocorridas", apresentadas por todas as sete professoras.

Há, também, um conjunto de indicações $(85,7 \%)$ sobrea necessi dade de o aluno de 4a série conhecer seu próprio corpo e del ecuidar adequadamente (cuidar e conhecer o próprio corpo). Emseguidaéapontado por $42,8 \%$ das professoras: reconhecer as DST, higiene, saúde, o que parece coerentequando se considera a fai xa etária desses al unos (10 a 14 anos).

No geral, constata-se certa coerência entreo queé estabel ecido nos Descritores de Ciências para a 4a série das Matrizes Curriculares de Referência (Pestana, 1999) - ("Terra e ambiente" e "Ser humano: desenvol vimento e saúde") que, por sua vez, está baseado nos PCN - , e os temas propostos pelas professoras. Nota-se, todavia, que suas indicações são amplas e pouco explícitas do queexatamente deveráser ensinado/aprendido, bem como em que nível (básico, operacional ou gl obal).

Em História, vários foram os conteúdos apontados, sobretudo as habilidades eatitudes que os al unos devem dominar ao término de uma 4a série, segundo as respostas individuais das professoras investigadas. Para a grandemaioria (85,7\%) a percepção espaçotemporal éum aspecto chaveaser dominado pelos al unos, de modo coerentecomo queé preconizado nos Parâmetros Curriculares $\mathrm{Na}$ cionais - História e Geografia (Inep, 2001), seguido deconhecer fatos históricos $(57,1 \%)$. Destaca-sea recomendação da importância de conhecer seu estado, sua História, os primeiros habitantes, os pioneiros, escravos, os bandeirantes e o progresso, por partededuas das professoras (28,6\%).

Em Geografia, de modo similar às respostas apresentadas com rel ação à História, as professoras apontaram muito mais a aquisição de um conjunto de habilidades que exigem estratégias deensino como a observação, descrição, experimentação ecomparação. Para desenvolvêlas parece ser necessário promover um clima declasse muito particular, uma vez que as habilidades indicadas referem-se, em grandeescala, a aspectos relativos à interação em sal a de aula eenvolvem não somente a relação professor - alunos, mas também a deal unos - al unos.

Mais especificamente, as professoras de 4a série parecem enfatizar os aspectos rel ativos à cidadania $(85,7 \%)$, à diversidade cultural e ambiental $(42,9 \%)$ e ao respeito e preservação ambiental (42,9\%). Cerca de $60,0 \%$ delas apontam ser rel evante que os al unos percebam as vinculações existentes entre a História e a Geografia, ou seja, a relação entre tempo e espaço na anál ise sobre o desenvol vimento do homem.

Tendo em consi deração os componentes aqui analisados, observa-se que as professoras, no geral, não indicaram o grau de complexidade com que os diferentes conteúdos deveriam ser domi nados pel os al unos ao final da $4^{a}$ série.

A seguir, apresenta-se o Quadro 1 que é produto da discussão das professoras sobre as bases de conhecimento de al unos de 4a série ao final do ano letivo. Destaca-se que a síntese col etiva apresentada parece avançar, em termos deabrangência, diversidadee grau decomplexidade, na indicação dos conteúdos consi derados relevantes, tendo em consi deração as suas indicações individuais. Em al guns casos as professoras acharam conveniente justificar suas decisões, explicitando de certa maneira o por que determi nados conteúdos devem ser ensinados. Isto parece ser um outro aspecto revelador de como concebem o que um aluno devesaber ecomo se configura a sua base de conhecimento para o ensino. 


\section{Quadro 1 - Base de conhecimento para al unos ao final da 4a série}

(continua)

\begin{tabular}{|c|c|}
\hline $\begin{array}{l}\text { Componente } \\
\text { Curricular }\end{array}$ & $\begin{array}{l}\text { O que um aluno de } 4^{a} \text { série deve saber ao final do ano letivo para ir bem } \\
\text { na série seguinte? }\end{array}$ \\
\hline $\begin{array}{l}\text { Língua } \\
\text { Portuguesa }\end{array}$ & $\begin{array}{l}\text { - Escrever um texto coeso, usando os sinais gráficos de pontuação. } \\
\text { Ele tem que distinguir textos narrativos, descritivos, poéticos, jornalísticos } \\
\text { e também com o recurso de diálogos. } \\
\text { - Fazer uso de concordância a fim de que a mensagem escrita seja } \\
\text { compreendida com clareza pelo leitor. } \\
\text { - Ser capaz de fazer leitura clara com entonação específica a cada tipo } \\
\text { solicitado, como ler versos com entonação característica, ler o texto em } \\
\text { prosa respeitando e entoando a pontuação grafada. } \\
\text { - A gramática está sendo cobrada e trabalhada no contexto de forma que, } \\
\text { o aluno, tem que conhecer o que a palavra representa na frase: } \\
\text { um substantivo, um adjetivo, pronome ou verbo. } \\
\text { - Ao fazer a leitura esse aluno tem que estar apto para compreendê-la. } \\
\text { Dialogar e criticar o texto identificando a mensagem informativa ou formativa } \\
\text { que essa leitura oferece. }\end{array}$ \\
\hline Matemática & $\begin{array}{l}\text { - Compreender e efetuar as técnicas operatórias das quatro operações } \\
\text { fundamentais e aplicá-las nas resoluções de problemas apresentados } \\
\text { nas diversas situações do cotidiano, ou seja, ganho, perda, compra, venda, } \\
\text { lucros envolvendo o sistema de numeração. } \\
\text { - Compreender o significado de números fracionários e decimais, assim como } \\
\text { aplicá-los nas quatro operações e resoluções de problemas, sendo o mais } \\
\text { concreto e da realidade do educando. } \\
\text { - Conhecer o valor posicional dos números e o sistema monetário atual, } \\
\text { aplicando e utilizando-os na forma de porcentagem, tendo uma noção mais } \\
\text { clara de lucros e prejuízos. } \\
\text { - Conhecer as unidades fundamentais de medidas, dos múltiplos e submúltiplos. } \\
\text { - Valorizar a geometria em sua vida cotidiana, observando-a nas construções, } \\
\text { de materiais, tais como, caixas de papelão, plásticos, brinquedos, moradias, } \\
\text { ruas, parques, veículos, campos de futebol, pistas de corridas, boliche, etc. } \\
\text { - Distinguir noções de perímetros e áreas das figuras geométricas, tais como: } \\
\text { quadrado, retângulo, triângulo, trapézio, paralelogramo assim como os } \\
\text { ângulos de } 45 \text { e } 90 \text { graus, reconhecimento de retas, curvas abertas } \\
\text { e fechadas aplicadas nas construções de sólidos e figuras criativas. } \\
\text { - Dominar as tabuadas. } \\
\text { Justificativa: Esses conteúdos são importantes para que os alunos possam } \\
\text { raciocinar com lógica e criatividade, para assim poder relacionar, } \\
\text { comparar, classificar, generalizar e criar. }\end{array}$ \\
\hline Ciências & $\begin{array}{l}\text { - Observar o mundo à sua volta, compreender a importância daquilo que cerca } \\
\text { o meio ambiente para a melhoria e conservação da vida no planeta, tendo } \\
\text { para isso oportunidades de criar conceitos: da Terra como planeta: planeta } \\
\text { este pertencente ao Sistema Solar, onde há uma camada de ar que o envolve } \\
\text { (atmosfera), que por conta de seus movimentos temos os dias e as noites, } \\
\text { as estações do ano, as fases da lua e suas influências nas marés. } \\
\text { Suas possibilidades de transformações, influências que pode sofrer, através } \\
\text { do tempo ou científicas os fenômenos da natureza (chuvas, enchentes, secas, } \\
\text { geadas, granizos nas regiões rurais e urbanas), os seres vivos, reprodução } \\
\text { animal e vegetal como continuidade e preservação da espécie e modificações } \\
\text { físicas e comportamentais do ser humano, assim como a importância e valor } \\
\text { do corpo humano fazendo com que o aluno consiga construir seu próprio } \\
\text { conhecimento através de pesquisa e orientações formativas e informativas } \\
\text { oferecidas pelo professor num linguajar acessível. } \\
\text { - Doenças Sexualmente Transmissíveis } \\
\text { Justificativa: Propiciar e desenvolver as noções de espaço, tempo, causalidade } \\
\text { naquilo que diz respeito à matéria, energia e transformações. } \\
\text { Interferir de modo crítico na realidade visando a melhoria de suas } \\
\text { condições de vida e de população. }\end{array}$ \\
\hline
\end{tabular}




\section{Quadro 1 - Base de conhecimento para alunos ao final da 4ạ série}

(conclusão)

\begin{tabular}{|c|c|}
\hline $\begin{array}{l}\text { Componente } \\
\text { Curricular }\end{array}$ & $\begin{array}{l}\text { O que um aluno de } 4^{a} \text { série deve saber ao final do ano letivo para ir bem } \\
\text { na série seguinte? }\end{array}$ \\
\hline História & $\begin{array}{l}\text { - O aluno tem que ter a noção espaço - temporal, a percepção de que o fato } \\
\text { presente se deve a um princípio do passado, ou seja, moro numa cidade que } \\
\text { faz parte de um estado que com outros formam o Brasil cujos primeiros } \\
\text { habitantes foram os índios. Através dos fatos históricos o aluno vai } \\
\text { conhecendo e fazendo parte dessa história, acrescentando a sua colaboração. } \\
\text { É preciso que antes de decorar datas, o aluno na } 4^{a} \text { série, conheça a } \\
\text { importância dos costumes e vivência que caracterizam as diferentes épocas } \\
\text { históricas. Ao adquirir esses conceitos o aluno estará apto para assimilar que } \\
\text { os fatos se deram e se dão dentro de um contexto temporal e espacial } \\
\text { envolvendo movimentos de população, condições de vida e análise do mapa } \\
\text { político do Brasil. Pesquisar fatos históricos - selecionar material, abstrair } \\
\text { conteúdos e elaborar textos próprios. } \\
\text { Justificativa: Levar o aluno a conhecer seu estado: sua história, os primeiros } \\
\text { habitantes, os pioneiros, os escravos, os bandeirantes e o progresso. } \\
\text { Descrever fatos que colaboram e ou fatos que dificultaram o desenvolvimento } \\
\text { de nosso estado e nosso país. }\end{array}$ \\
\hline Geografia & $\begin{array}{l}\text { - Como é um componente que se relaciona muito com História. } \\
\text { O aluno precisa compreender as mudanças efetuadas pelo tempo, pelo } \\
\text { homem na natureza, pelas mudanças de relevo, regiões. } \\
\text { - Compreender a ação crítica de seu papel de cidadão atuante e agente } \\
\text { transformador de ambiente. } \\
\text { - Identificar as mudanças e os possíveis elos que possas ser feitos nos } \\
\text { diferentes ambientes. } \\
\text { - Entender a interdependência campo cidade. } \\
\text { - Perceber-se cidadão e parte integrante de um grupo social. } \\
\text { - Conhecer e valorizar a diversidade do patrimônio sociocultural brasileiro } \\
\text { e municipal, bem como a diversidade de nossa natureza. } \\
\text { - Valorizar o uso de técnicas e tecnologias em prol da preservação } \\
\text { e desenvolvimento da melhoria da qualidade de nossa vida. }\end{array}$ \\
\hline
\end{tabular}

\section{A construção de indicadores educacionais por professores: algumas considerações sobre um processo}

Em linhas gerais a indicação do que umacomunidadeescolar considera rel evante que seus al unos aprendam - aqui compreendido como a construção de indicadores educacionais - pareceu ser um mecanismo importante de apoio aos processos col etivos de tomada de decisões rel acionadas ao currículo a ser desenvolvido pelas professoras investigadas eem rel ação ao seu processo de desenvolvimento profissional. De um lado, esse processo possibilitou o estabelecimento, ainda que por vezes incipiente, de el ementos constitutivos do projeto pedagógico da escola. Deoutrolado, provocou dinâmicas detrocas enegociações entre as diversas participantes, a respeito do que consideram necessário que seus alunos aprendam e possivel mente promoveu aprendizagens entre os pares.

A seguir apresentamos al gumas considerações envolvendo todas as séries e os diferentes componentes curriculares, a partir da experiência de ensino e aprendizagem rel atada. São apontados aspectos avaliados como relevantes eque devem ser consi derados nos processos de construção col etiva deindicadores educacionais por uma comunidadeescolar.

Nessa experiência deensino eaprendizagem foram construídos indicadores sobre o que os al unos devem aprender nas séries iniciais do ensino fundamental, segundo o ponto de vista de um conjunto de professoras de um determinado contexto escolar. Mais precisamente, as professoras definiram 
os objetivos dos diferentes componentes curriculares considerando cada uma das quatro séries. Esse parece um passo preliminar para definir-se adequadamente, no âmbito da unidadeescolar, o quanto, ocomo eo por que os alunos devem aprender. Evidenciou-se que o material produzido passou a ser referência importantepara a escola e para o coletivo de suas professoras, tanto para o planejamento das atividades didáticas como para a avaliação do trabal ho peda gógico real izado ao longo das quatro séries.

Ao se considerar a opção daquela comunidadeescolar por definir as séries anuais e sucessivas como os períodos temporais adequados para a progressão continuadano primeiro ciclo, observou-sebaixo grau de diferenciação sobre o que os al unos deveriam aprender nas diferentes etapas, se consideradas as respostas individuais e coletivas das professoras. Possivelmente essa característica se relacioneao caráter flexível do ensino em ciclos, ao pressuposto de que não há um tempo previamente determinado para que as aprendizagens ocorram ejustifique o fato dequeas classes eram al gumas vezes compostas por grupos de alunos com repertórios bastante heterogêneos.

Os dados obtidos permitiram conhecer o que as professoras individualmente consi deravam rel evanteensinar nas quatro primeiras séries do ensino fundamental. Possibilitaram, igual mente, apreender aspectos que parecem influenciar o conteúdo de ensino e o tipo de ensino por elas ministrado.

Em linhas gerais evidenciou-se que:

1. Foram apresentadas respostas individuais pouco elaboradas e explicativas a respeito do que um aluno deve saber ao final de uma dada série, tendo em vista seu bom desempenho na série seguinte.

2. As professoras atribuem importância mai or aos conteúdos ehabilidades re laci onados com Língua Portuguesa e Matemática- nestaordem-, independentemente da sérieconsi derada.

3. No caso dos demais componentes, para a consecução dos objetivos indicados, pareceser necessária a existência deuma culturaescolar quenão parece, a princípio, corresponder às práticas cotidianas de sal a deaula da escola, na qual essa investi gação foi realizada. A sua indicação parece constituir mais uma "declaração de intenções" do que propriamenteum rol de objetivos trabal hados ou a serem efetivamenteatingidos pelas professoras, dada a abrangência com que os objetivos pretendidos foram apontados e, sobretudo, o tipo de habilidades a el es relacionadas.

4. A partir das observações anteriores infere-se que, nos casos de Língua Portuguesa eMatemática, as recomendações das professoras parecem representar mais micro-objetivos do que macroobjetivos, discutidos por Giroux (1997), demaneira diversa ao observado em Geografia, Ciências e História, especial mente no caso das $3^{\mathrm{a}}$ e $4^{\mathrm{a}}$ séries. Ao se considerarem as Matrizes Curriculares de Referência (Pestana, 1999), no caso dos dois componentes privilegiados (Língua Portuguesa e Matemática, nessa ordem) as respostas mais freqüentes parecem inserir-seno nível básico, seguido do operacional. Para os demais componentes há uma ênfase, possivel mente inadequada - tendo em vista as séries consideradas - , de conhecimentos mais relacionados aos níveis operacional egl obal.

5. Os pontos de chegada intermediários definidos podem ser entendidos como pertinentes a quaisquer das quatro séries do ensino fundamental. Essa constatação, aliada às di scussões realizadas no grupo, permitiu confirmar a percepção de que as séries seguintes vão sendo responsabi lizadas pel o que as anteriores não conseguirem ensinar. Chega-se, assim, ao limite de ter na 4a série al unos ainda não alfabetizados.

Ao considerar-sea natureza das respostas individuais apresentadas por parte das professoras no processo de construção de indicadores educacionais, três hipóteses, não necessariamenteexcludentes, puderam ser estabel ecidas.

A primeira relaciona-se ao grau e extensão em que as professoras dominam os conteúdos, do ponto de vista conceitual dos componentes curriculares, e ao repertório individual das diferentes professoras. $\mathrm{O}$ domínio precário do conteúdo, observado emal gumas professoras, al iado a condições detrabal ho nem sempreadequadas (número deal unos por classe, jornada de trabal ho, 
carência deespaços detrabal ho individual e coletivo voltados especificamente para questões pedagógicas, entre outras) pode contribuir para a indiferenciação dos pontos de chegada intermediários defini dos.

A segundahipóteseestá relacionada ao fato de que em Língua Portuguesa e Matemática as respostas apresentadas parecem corresponder a al go mais concreto efactível do que os objetivos apontados para os demais componentes curriculares. Nesses casos as respostas corresponderam supostamente a eventos ou atividades usuais de sala de aula. A pesar da indiscutível relevância dos objetivos apontados quando se considera essa fase da escol aridade, não se observam, por exemplo, as conexões "entre os métodos, conteúdos e estrutura de um curso ea sua importância para a real idadesocial mais ampla" (Giroux, 1997, p. 8) nas respostas das professoras. Embora ler, escrever efazer contas componham conteúdos e habilidades essenciais para a escolaridade posterior, a ausência da especificação deseu nível deocorrência ao Iongo de quatro séries dificul ta a definição dos pontos de chegada intermediários. Não pareceespeculação supor que a mai or parte das atividades desenvolvidas em sal a de aula se relaciona mais freqüentemente a esses dois componentes e é provável que as respostas ofereci das correspondam com mai or precisão ao que efetivamente ocorre em sal a deaula eaquilo queas professoras dominam (ou acreditam dominar) pedagogicamente.

Em História, Geografia eCiências, apesar da rel evância social dos conteúdos assinal ados, grande parte dos objetivos parece mais difícil de ser concretizado dada a sua complexidadee amplitudee, especialmente, por exigir estratégias deensino com el es coerentes. Caso ocorressem com alta freqüência no cotidiano das sal as de aula, também deveriam consistentemente estar presentes nas respostas apresentadas para Língua Portuguesa e Matemática. É possível, pel o fato de aquel es componentes serem menos trabal hados, val orizados edominados, que as professoras não sesintam tão à vontade para se referirem e/ou reportarem a eles. Tal suspeita se baseia na observação de que as professoras, nestes casos, para cumprirema tarefa proposta, buscaram referências de apoio externas, como livros didáticos, apostilas, anotações de orientações técnicas etc e, por isso, suas respostas apresentem aparentemente um grau maior de elaboração, envolvam ações mais complexas e possivel mente de mai or valor social.

Uma terceira hipótese explicativa do tipo deresposta individual obtida, tendo em vista os diferentes componentes, relacionase à tarefa proposta que consiste em traduzir, por meio depal avras, eventos que ocorrem na prática e, decerta maneira, explicitar o seu conhecimento pedagógico de conteúdo (Shulman, 1987, 1986). Dito de outra forma, tendo em vista as exigências postas pelas tarefas solicitadas, parece ser difícil transformar as ações coti dianas relacionadas ao ensinar - muitas vezes aparentemente desconectadas entresi, sem uma lógica aparente - em "teorias coerentes e consistentes". Consi derando novamenteas respostas apresentadas em Língua Portuguesa e Matemática, pareceu ser mais fácil para as professoras investigadas escreverem sobre o que caracteriza o seu cotidiano. Assim, os indicadores construídos para esses componentes apresentam-se coerentes com o que provavel mente as professoras real izam em suas classes e poderiam ser, assim, indicadores do currículo implementado. Quanto aos indicadores el aborados para Ciências, História eGeografia - como foram aparentemente definidos a partir de consultas a fontes externas à prática das professoras - , apresentam possivel mente uma baixa correspondência com o queocorre nas sal as de aula. Nesses casos, os indicadores estabelecidos possivel mente mantêm um grau de correspondência baixo com o ensino promovido desses conteúdos e poderiam, então, ser entendidos como indicadores do currículo pretendido, conformeas definições dePorter eSmithson (2001).

Os processos de discussão grupal ede produção das respostas coletivas por série evidenciaram a rel evância dessetipo deiniciativa, dado o grande envol vimento observado por parte das professoras. As dinâmicas propostas permitiram o acesso - e possíveis novas aprendizagens - a um conjunto de diferentes informações provenientes de diversas fontes - no caso, professoras e séries, considerando-se aquele contexto escolar em específico. Observou-sequeas tentativas de comunicar formal mente o que se espera dosal unos pareceser importante, não apenas para situar as professoras individual menteeem grupo em relação ao currículo desenvolvido/pretendido, mas, sobretudo, pela possibilidade de expor idéias pessoais à análise crítica dos pares. 
Um aspecto a ser destacado, a partir dos dados desse trabalho, diz respeito à implementação de políticas públicas pelas comunidades escolares. Esseéum processo sujeito a diferentes graus e níveis de traduções, todas el as atravessadas pelas crenças, teorias pessoais, conhecimentos das pessoas envolvidas, bem como pelas condições situacionais efetivas em que as práticas pedagógicas se produzem.

Em síntese, a real ização dessa experiência de ensino e aprendizagem foi potencial menterel evantee profícua para melhor conhecer-seo trabal ho das professoras, suas concepções, suas crenças. A sua realização permitiu, entre outras coisas, o estabel ecimento de uma dinâmica importante detrocas entre as professoras, inclusive de diversos ti pos deconhecimento profissional, o que favorecea construção de uma verdadeira cultura deaprendizagem entre os pares ou de aprendizagem organizacional. Possibilitou o estabel ecimento de condições de trabal ho mais favorecedoras do desenvolvimento profissional no plano pessoal e coletivo.

Por meio dos processos desenvol vidos, foram possivel mente estabel ecidas condições favorecedoras para quenovas concepções sobre os al unos eo ensino pudessem ser estabel ecidas por parte das professoras, tendo em vista as características daquela escola em particular. Espera-sequetais idéias sejam mais consistentes em relação aos al unos e eventos de sal as deaula, li bertando as professoras de visões restritivas sobre o potencial humano, sobre a motivaçãoe, especial mente, sobrea avaliação da aprendizagem.

Independentemente do fato de al guns elementos importantes para a construção de indicadores de currículo não terem sido, nessa experiência de ensino eaprendizagem, indicados - como éo caso da determinação precisa do grau de complexidade, do como e do por que dos conteúdos definidos - , evidenciou-se sua potencial idade tanto no que diz respeito à definição de um quadro de referências sobre os conteúdos instrucionais desenvolvidos emsal as deaula e, respectivamente, na determinação deuma ferramenta para a tomada de decisões a respeito das aprendizagens dos alunos e o monitoramento do ensino promovido (Porter, Smithson, 2001). Em linhas gerais, pode-se afirmar que foi possível a construção das bases para a progressão continuada, conforme objetivado por aquela comunidade escolar.

Por meio dos processos envolvidos para a elaboração desses indicadores, foram estabel ecidas condições adequadas para a continuidade do projeto de pesquisa-intervenção conduzido pel as professoras, para a promoção de seu desenvolvimento profissional, sobretudo no que diz respeito ao domínio do conteúdo específico, e para a construção do projeto pedagógico da escola. Diante desses resultados, advoga-se que a elaboração de indicadores educacionais por uma comunidade escolar é uma tarefa potencial mentecontributiva ao desenvolvimento profissional da docência e possível deser realizada.

\section{Referências bibliográficas}

ARGYRIS, C.; SCHÖN, D. A. Organizational Learning II. Theory, method and practice. Reading (Ma): Addisson-Wesley Publishing Company, 1996.

BOTTANI, N. E.; TUIJNMAN, A. International Educational Indicators: framework, development and interpretation. In: ORGANISATION FOR ECONOMIC CO-OPERATION AND DEVELOPMENT (OCDE). Making Education Count. Paris, 1994. p. 21-35.

PESTANA, Maria Inês Gomes deSá et al. Matrizes curriculares de referência para o Saeb. Ed. rev. ampl. Brasília: Instituto Nacional de Estudos ePesquisas Educacionais, 1999.

BRYK, A. A.; HERMANSON, K. M. Educational Indicator Systems: observations on their structure, interpretation, and use. Review of Research in Education, 19, p. 451-484, 1993. 
COLE, A. L.; KNOWLES, J. G. Teacher Development Partnership Research: a focus on methods and issues. American Educational Research Journal, v. 30, n. 3, p. 473-495, 1993.

ERAUT, M. Indicators and accoutability at the school and classroom level. In: ORGANISATION FOR ECONOMIC CO-OPERATION AND DEVELOPMENT (OCDE). Making Education Count. Paris, 1994. p. 21-35.

GIMENO SACRISTÁN, J. Currícul o e diversidadecultural . In: SILVA, T. T. da; MOREIRA, A. F. (Org.). Territórios contestados: o currículo e os novos mapas políticos e culturais. Petrópolis, RJ: Vozes, 1995.

GIMENO SACRISTÁN, J.; PÉREZ GOMÉZ, A. I. Compreender e transformar o ensino. Trad. Ernani F. da Fonseca Rosa. 4. ed. Porto Alegre: ArtMed, 1998.

GIROUX, H. A. Superando objetivos behavioristas e humanísticos. In: GIROUX, H. A. Os professores como intelectuais. Trad. Daniel Bueno. Porto Alegre: Artes Médicas, 1997.

INSTITUTO NACIONAL DE ESTUDOS E PESQUISAS EDUCACIONAIS ANÍSIO TEIXEIRA. Introdução aos Parâmetros Curriculares Nacionais. 3. ed. Brasília: MEC/ SEF, 2001. SEF, 2001.

Parâmetros curriculares nacionais: Ciências Naturais. 3. ed. Brasília: MEC/ SEF, 2001.

Parâmetros curriculares nacionais: História e Geografia. 3. ed. Brasília: MEC/ SEF, 2001.

Parâmetros curriculares nacionais: Língua Portuguesa. 3. ed. Brasília: MEC/ Parâmetros curriculares nacionais: Matemática. 3. ed. Brasília: MEC/SEF, 2001.

KNOWLES, J. G.; COLE, A. L.; PRESSWOOD, C. S. Through Preservice Teachers' Eyes: experience through narrative and inquiry. New York: McMillan College Publishing Co., 1994.

LUCKESI, C. C. Avaliação da aprendizagem escolar: estudos e proposições. São Paulo: Cortez, 1995.

MCDIARMID, G. D. Realizing new learning for all students: a framework for the professional devel opment of Kentucky teachers. National Center for Research on Teaching Learning (NCRTL), 1995.

MIZUKAMI, M. G. N. et al . A reflexão sobre a ação pedagógica como estratégia de modificação da escola pública elementar numa perspectiva de formação continuada no local de trabal ho. São Paulo: Fapesp, 1998. Relatório de Pesquisa 2.

Escola e aprendizagem da docência: processos de investigação e formação. São Carlos, SP: EDUFSCar, 2002.

NACIONAL RESEARCH COUNCIL. Committee on Indicators of PrecollegeScienceand Mathematics Education. Improving Indicators of the Quality of Science and Mathematics Education in Grades K-12. 1988. Disponível em: <http://www.nap.edu.openbook/ 0309037409/html/120.html >

OGAWA, R.; COLLON, E. Educational Indicators: What are they? How school s and school districts use them?, 1998. Disponível em: <http: cerc.ucr.edu/publications/PDF_Transfer/ School_Organizations/so004_educational_indicators/so004_educational_indicators.PDF > 
PERRENOUD, P. Avaliação: da excelência á regulação das aprendizagens - entre duas lógicas. Trad. Patrícia Chittoni Ramos. Porto Alegre: Artes Médicas Sul, 1999.

PERRENOUD, P. 10 novas competências para ensinar. Trad. Patrícia Chittoni Ramos. Porto Alegre: Artes Médicas Sul, 2000.

PORTER, A.; SMITHSON, J. Defining, Developing, and using Curriculum Indicators RR 048 - December 2001. Disponível em: <http://www.cpre.org/Publications/rr48.pdf>

REALI, A. M. M. R. Indicadores Educacionais, Professores e a Construção do Sucesso Escolar. Ensaio: avaliação e políticas públicas em Educação, v. 9, n. 30, p. 79-108, 2001.

SÃO PAULO. Secretaria Estadual de Educação do Estado de São Paulo. Escola de Cara Nova. Planejamento/98. Subsídios para implantação do regi me de progressão continuada no ensino fundamental - organização e funcionamento do ensino médio, 30, p. 79-108, 1998.

SCHOENFELD, A. H. Toward a theory of teaching-in-context. Disponível em: <http:// www.gse. berkel ey. edu/Facul ty?aschoenfel d?TeachContext?teaching-in-context.html > Acessado em: 1997.

SHULMAN, L. S. Knowledge and teaching: foundations of a new reform. Harvard Educational Review, v. 57, n. 1, p. 1-22, 1987.

Those who understands: knowledge growth in teaching. Educational Researcher, v. 17, n. 1, p. 4-14, 1986.

ZABALA, A. A prática educativa: como ensinar. Trad. Ernani F. da F. Rosa. Porto Alegre: ArtMed, 1998.

ZEICHNER, K. M. Educating teachers for cultural diversity. NCRTL Special Report, 1992. $37 \mathrm{p}$.

Aline Maria de Medeiros Rodrigues Real i, doutora em Psicol ogia Experimental pela Universidade de São Paulo (USP), é professora da Universidade Federal de São Carlos (UFSCar).

Claudia Raimundo Reyes, doutora em Educação pela Universidade Federal de São Carlos (UFSCar), da qual éprofessora.

Elisabeth Márcia Martucci, doutora em Educação, pela Universidade Federal deSão Carl os (UFSCar), é presi dente ediretora executiva da Fundação Educacional São Carlos/ Prefeitura Municipal deSão Carlos (SP).

Maria da Graça Nicoletti Mizukami, doutora em Educação pela Pontifícia Universidade Católica do Rio de Janei ro (PUC-Rio), é professora da Universidade Estadual Paulista Júlio de Mesquita Filho (Unesp)/Campus de São J osé do Rio Preto e professora vol untária do Programa de Pós-Graduação em Educação daUFSCar.

Emília Freitas de Lima, doutora em Educação pel aUniversidade Federal deSão Carlos (UFSCar), da qual é professora.

Regina Maria Simões Pucinelli Tancredi, doutora em Educação pela Universidade Federal de São Carlos (UFSCar), da qual é professora.

Roseli Rodrigues de Mello, doutora em Educação pela Universi dade Federal deSão Carlos (UFSCar), da qual éprofessora. 


\section{Abstract "What knowledge base my pupils must have?": an experience of teaching and learning the construction of educational indicators}

This paper aims at pointing out some aspects related to the collective construction of educational indicators by teachers. The data were obtained through teaching and learning experiences conducted by a group of teachers from a public school of the state of São Paulo. To enrich the discussion, we now present the constructed indicators for the different curricular components considering the $4^{\text {th }}$ grade of primary education. It was possible to evidence the potentiality of the educational indicators construction processes for the definition of a framework to specify the curricular contents that can be taught in classrooms, of a tool to monitor pupils' learning (Porter and Smithson, 2001) and the continued progression according to the school community. Important subsidies for the teachers' professional development and for the construction of the school pedagogical project were also evidenced.

Keywords: educational indicators; knowledge basis; teachers training; continued progression; primary school.

Recebi do em 19 de maio de 2003.

A provado em 16 de março de 2004. 